\title{
Análise da comunicação verbal e não verbal de uma mãe cega e com limitação motora durante a amamentação
}

\author{
Analysis of the verbal and non-verbal communication of a blind mother \\ with motor impairment during breastfeeding \\ Análisis de la comunicación verbal y no-verbal de una madre ciega y con \\ limitación motora durante la lactancia
}

\section{Lorita Marlena Freitag Pagliuca', Giselly Oseni Laurentino Barbosa", Luana Duarte Wanderley", Paula Marciana Pinheiro de Oliveira"'I}

\author{
' Universidade Federal do Ceará. Departamento de Enfermagem. Programa de Pós-Graduação em Enfermagem. \\ Fortaleza-CE, Brasil. Pesquisadora do CNPq. \\ "Universidade Federal do Ceará. Departamento de Enfermagem. Fortaleza-CE, Brasil. \\ Bolsistas de Iniciação Científica do CNPq. \\ I'I Universidade Federal do Ceará. Departamento de Enfermagem. Programa de Pós-Graduação em Enfermagem. \\ Fortaleza-CE, Brasil. Doutoranda. Bolsista CNPq.
}

Submissão: 12/9/2009 Revisão: 20/7/2010 Aprovação: 5/12/2010

\section{RESUMO}

Análise da comunicação verbal e não verbal de mãe cega e com limitação motora durante a amamentação. Coleta por entrevista e filmagem, com análise qualitativa dos dados. Na comunicação verbal a mãe atua como remetente durante amamentação e uso da mamadeira, predominando a mensagem dificuldade de amamentar. Na não verbal, na posição deitada há ausência de contato face a face e diminui o contato físico; sentada, o contato está aumentado, expressa afeto, mas a mãe não direciona a face para o filho; administrando mamadeira, mãe sentada, expressa afeto e interação, mantém cabeça baixa. Conclui-se que a comunicação verbal está centrada na mensagem alimentação e na não verbal há interferência da posição para alimentar a criança.

Descritores: Comunicação; Portadores de deficiência visual; Aleitamento materno.

\section{ABSTRACT}

Analysis of the verbal and non-verbal communication of a blind mother with motor impairment during breastfeeding. Data were collected through interview and recording, with qualitative analysis. In verbal communication, the mother is the sender during breastfeeding and bottle-feeding, and the main message refers to breastfeeding difficulties. In non-verbal communication, in the lying position, there is a lack of face-to-face contact and physical contact is reduced; in the sitting position, contact increases, expresses affection, but the mother does not direct her face to her child; bottle-feeding, the mother in the sitting position, expresses affection and interaction, with the head lowered. It is concluded that verbal communication is centered on the feeding message; in non-verbal communication, the position to feed the child interferes.

Descriptors: Communication; Visually impaired persons; Breastfeeding.

\section{RESUMEN}

Análisis de la comunicación verbal y no-verbal de madre ciega y con limitación motora durante la lactancia. Datos recolectados por entrevista y filmación. Análisis cualitativo. En la comunicación verbal, la madre es remitente durante la lactancia y el uso del biberón, el mensaje predominante es la dificultad de amamantar. En la no verbal, posición acostada, hay ausencia de contacto cara a cara y el contacto físico está disminuido; sentada, el contacto aumentado, expresa afecto, pero la madre no dirige la cara al hijo; administrando biberón, sentada, expresa afecto e interactúa con el hijo, cabeza baja. Se concluye que la comunicación verbal está centrada en el mensaje alimentación y que, en la no verbal, interfiere la posición para alimentar el niño.

Palabras clave: Comunicación; Personas con daño visual; Lactancia materna. 


\section{INTRODUÇÃO}

A amamentação é um processo natural. Entretanto requer ajuda para ser feita corretamente, com seguimento no domicílio e na unidade de saúde, com vistas a prevenir problemas na mama puerperal e o desmame precoce ${ }^{(1)}$. Como amplamente difundido, a amamentação traz benefícios biológicos para o filho e é uma importante atividade de interação mãe e bebê, pois favorece a comunicação e propicia a formação de laços afetivos. Durante esta atividade, a criança é abraçada, trazida junto ao corpo da mãe, é acariciada e constantemente a mãe fala com ela. Há toda uma preparação da mãe e da criança para a comunicação e profundos laços afetivos são estabelecidos.

Quando os pais são pessoas com deficiência (PcD) este fato pode interferir no cuidado dos filhos e é fundamental que os profissionais de saúde, sobretudo o enfermeiro, avaliem suas dificuldades, porquanto, mesmo nessa condição, podem exercer sua função essencial de cuidar. Embora aos cegos falte a visão, eles utilizam o tato, a audição e o olfato com maior precisão. Mulheres cegas necessitam da mesma atenção dispensada às videntes e esta deve ser enriquecida pelo toque. Em estudo anterior conduzido por uma das autoras, conforme mães cegas relataram, não houve orientação adequada à sua condição, particularmente nos primeiros dias de vida do filho.

Como um processo composto de formas verbais e não verbais, a comunicação é utilizada com o propósito de partilhar informações. Enquanto a comunicação verbal refere-se à linguagem escrita e falada, aos sons e palavras usadas para se comunicar, a não verbal refere-se a toda informação decorrente de expressões faciais, postura, vestimenta, organização do ambiente, entre outros elementos. Neste estudo serão adotados referenciais teóricos específicos para discutir a comunicação verbal e a não verbal, descritas em seguida.

\section{A comunicação verbal}

Na Teoria da Comunicação Verbal são imprescindíveis seis elementos para a ocorrência de um ato de comunicação. São eles: remetente, destinatário, mensagem, contexto, código e contato. Remetente ou emissor é todo aquele indivíduo ou grupo que envia uma mensagem a um ou mais receptores. O emissor corresponde à primeira pessoa do verbo, o EU ou NÓS; é aquele que fala. Destinatário ou receptor é o indivíduo ou grupo que recebe a mensagem. Corresponde à segunda pessoa do discurso, TU ou VÓS; é aquele com quem se fala. A mensagem é o ato da fala, conjunto de enunciados. Falar significa selecionar e combinar signos. Portanto, mensagem é a seleção e combinação de signos realizada por determinado indivíduo. Mensagem é o conceito que se passa para o receptor. Contexto ou referente é o conteúdo, assunto, da mensagem. Corresponde à terceira pessoa do discurso, é algo ou alguém de que se fala, é o objeto da mensagem. O código é a língua com que se fala; é o instrumento da fala, é um conjunto de signos convencionais e sua sintaxe, que deve ser total ou parcialmente comum ao emissor e ao receptor. Por contato ou canal, entende-se o meio físico por onde passa a mensagem entre o emissor e o receptor. Quanto à forma, o meio físico pode ser sonoro ou visual, e é também a conexão psicológica entre emissor e receptor ${ }^{(2)}$.
A função referencial está relacionada com alguém ou algo de que se fala, é o denominado contexto da mensagem, quando existe a troca de informações. No remetente encontra-se a função emotiva ou expressiva, a qual visa uma expressão direta da atitude de quem fala em relação àquilo de que se está falando. Tende a suscitar a impressão de certa emoção, verdadeira ou simulada. O estrato puramente emotivo da linguagem é apresentado pelas interjeições. Estas diferem dos procedimentos da linguagem referencial, particularmente pela sua configuração composta por seqüências sonoras peculiares ou mesmo sons incomuns. A função emotiva, evidenciada pelas interjeições, dá colorido às manifestações verbais ${ }^{(2)}$.

\section{A comunicação não verbal}

A comunicação não verbal é carregada de significados. Mais emocional e sensitiva, é o elemento de surpresa que interfere na comunicação verbal, embora esta última seja mais consciente e programada. Na maioria das vezes, a comunicação não verbal é expressa sem que estejamos conscientes do que estamos emitindo ${ }^{(3)}$. Inúmeros sinais não-verbais reforçam, substituem ou contrariam a fala; os gestos, a expressão facial, a postura (movimentos e inclinações do corpo), a ocupação do espaço, o toque, principalmente quando substitui o olhar, quando há limitação visual.

De acordo com a literatura, a abordagem da comunicação não verbal é feita pela Teoria Proxêmica, a qual avalia a posição corporal e as relações espaciais do indivíduo como elaboração da cultura onde está inserido. Na análise proxêmica estão presentes oito fatores que compõem suas categorias primárias: 1. Postura-sexo: analisa o sexo dos participantes e a posição básica dos interlocutores (de pé, sentado, deitado); 2 . Eixo sociofugo-sociopeto: o eixo sociofugo demonstra o desencorajamento da interação enquanto o sociopeto implica o inverso. Essa dimensão analisa o ângulo dos ombros com relação a outra pessoa; a posição dos interlocutores (face a face, de costas um para o outro ou, qualquer outra angulação); 3 . Cinestésico: analisa o contato físico a curta distância, como o toque ou o roçar da pele, e o posicionamento das partes do corpo; 4. Comportamento de contato: este fator analisa as formas de relações táteis, como acariciar, agarrar, apalpar, segurar demoradamente, apertar, tocar localizado, roçar acidental ou nenhum contato físico; 5 . Código visual: verifica o modo do contato visual nas interações, como o olho no olho, ou a ausência de contato; 6 . Código térmico: detém-se no calor percebido pelos interlocutores; 7 . Código olfativo: analisa as características e o grau de odor sentido pelos interlocutores; 8. Volume da voz: analisa a percepção dos interlocutores com relação ao volume e intensidade da fala utilizada pelos interlocutores ${ }^{(4)}$.

Quanto à classificação das distâncias interpessoais na Teoria Proxêmica, divide-se em: Distância íntima (de 0 a 50cm) na qual ocorrem o contato físico, a percepção do calor humano, a transmissão dos odores e os encontros pessoais mais íntimos; Distância pessoal $(50 \mathrm{~cm}$ a $1,20 \mathrm{~m})$, embora próxima, pode não acontecer o contato físico, e os odores e o calor do corpo não serem mais sentidos; Distância social $(1,20 \mathrm{~m}$ a $3,60 \mathrm{~m})$, marcada, sobretudo, pelo contato visual com o 
interlocutor; Distância pública (acima de 3,60m), ocorre nos comícios e conferências, e nela o contato visual é coletivo ${ }^{(4)}$.

Objetivou-se analisar a comunicação verbal e não verbal de uma mãe cega e com limitação motora durante a amamentação.

\section{METODOLOGIA}

Trata-se de um estudo de caso que, em geral, representa a estratégia mais utilizada quando se colocam questões do tipo "como" e "por quê", quando o pesquisador tem pouco controle sobre os acontecimentos e quando o foco se encontra em circunstâncias contemporâneas dentro de algum contexto da vida real ${ }^{(5)}$. No referente à pesquisa com seres humanos, esta deve ser diferenciada da prática assistencial, porém ambas se destinam a contribuir diretamente para a saúde de indivíduos e comunidades.

O sujeito do estudo foi uma mulher cega, paraplégica e com limitação motora em membros superiores. Selecionada de forma intencional considerando as referidas limitações e a necessidade de acompanhamento de enfermagem no cuidado do filho de dois meses. Como local de estudo escolheu-se seu domicílio, com visitas semanais de abril a junho de 2008. A mãe cega, que recebeu o pseudônimo de Esperança, foi entrevistada para informar nome, idade, naturalidade, causa e tempo da cegueira, história da gestação, idade da criança, dificuldades e soluções encontradas para amamentar. Esperança relatava os fatos ocorridos a cada semana. Nestas oportunidades, as visitas eram gravadas e filmadas.

Como exigido, o projeto foi aprovado pelo Comitê de Ética em Pesquisa da Universidade Federal do Ceará-UFC, sob $n^{\circ} 1143 / 07$, sendo respeitados os princípios éticos e colhida assinatura do Termo de Consentimento Livre e Esclarecido, depois de lido e explicado ao sujeito do estudo com presença de testemunha vidente.

Depois de transcritos, os dados foram lidos repetidas vezes e organizados em quadro de acordo com os referencias teóricos da comunicação verbal e não verbal. A análise seguiu o método descritivo mediante comparação e análise reflexiva da literatura existente para a validação dos achados.

\section{RESULTADOS E DISCUSSÃO}

Esperança tem 21 anos de idade, é analfabeta, mas freqüentou escola especial para deficientes visuais. Nasceu cega em decorrência de uma paralisia cerebral e, além disso, porta deficiência em membros inferiores (paraplegia) e limitação em membros superiores. Reside com os avós e uma prima (irmã de criação) em domicílio próprio, composto por quatro cômodos. A situação socioeconômica da família é precária. Dispõem, apenas, de dois salários mínimos: um de Esperança e outro da avó.

Por ser acamada e cadeirante, Esperança permanece a maior parte do tempo em seu quarto que não atende aos requisitos de acessibilidade à sua locomoção, devido ao espaço reduzido, condições do piso e a presença de móveis. Sua avó, que Esperança chama de "mãe" por criá-la desde seu nascimento, é quem cuida da sua higiene pessoal e prepara sua alimentação. Sua locomoção dentro de casa depende da avó, que a carrega nos braços. Sua gravidez foi decorrente de uma relação amorosa com o marido da sua tia (filha da sua avó). Fez pré-natal e se submeteu a mais de seis consultas e aos devidos exames. O parto foi cesário e sem complicações. Nasceu um menino. Em conseqüência da limitação, Esperança o segura com certa dificuldade.

Ao nascer, a criança media 51 centímetros e pesava $2,500 \mathrm{~kg}$. No início deste estudo, tinha um mês e dezessete dias. Naquela ocasião, havia sido vacinada, pesava $3,300 \mathrm{~kg}$ e estava em amamentação exclusiva, mas chorava muito durante a mamada. Sempre auxiliada pela avó, Esperança exerce os cuidados com a criança relativos a banho e alimentação. O relacionamento entre Esperança, a criança e a avó, pode ser descrito como satisfatório, pois a avó demonstrava atenção e carinho com a neta e o bisneto, porém percebia-se receio da avó em permitir que Esperança cuidasse do filho. Como mencionado, o processo de comunicação engloba aspectos verbais e não verbais e são simultâneos. Para facilitar a interpretação dos resultados, primeiro se apresenta a abordagem verbal e, em seguida, a não verbal.

\section{Comunicação verbal}

A análise do processo de comunicação verbal está sintetizada em três quadros. Nos dois primeiros estão presentes os elementos da comunicação mãe, filho e enfermeira. No primeiro quadro, Esperança está amamentando e, no segundo, dando leite artificial em mamadeira. No terceiro quadro estão expostas as funções das mensagens emitidas pela mãe, devidamente analisada.

\begin{tabular}{|l|l|l|l|}
\hline $\begin{array}{l}\text { Elementos da } \\
\text { Comunicação }\end{array}$ & \multicolumn{1}{|c|}{ Mãe } & \multicolumn{1}{|c|}{ Criança } & \multicolumn{1}{|c|}{ Enfermeira } \\
\hline Remetente & $\begin{array}{l}\text { Está pegando. Mas } \\
\text { eu acho que ele } \\
\text { vai soltar. Olha, } \\
\text { ele vai começar a } \\
\text { chorar. }\end{array}$ & $\begin{array}{l}\text { A criança } \\
\text { chora. (Ela tenta } \\
\text { pegar o seio } \\
\text { da mãe). Emite } \\
\text { ruídos. }\end{array}$ & $\begin{array}{l}\text { Segura ele assim. } \\
\text { Abraça. Calma... } \\
\text { Vocế está mais } \\
\text { ansiosa do que ele. }\end{array}$ \\
\hline Destinatário & $\begin{array}{l}\text { Criança/ } \\
\text { Enfermeira }\end{array}$ & Mãe & Mãe \\
\hline Consagem & $\begin{array}{l}\text { Dificuldade em } \\
\text { amamentar. }\end{array}$ & $\begin{array}{l}\text { Incomodo. } \\
\text { Desconforto. }\end{array}$ & $\begin{array}{l}\text { Orienta como } \\
\text { segurar a criança. } \\
\text { Tranqüiliza a mãe }\end{array}$ \\
\hline Código & Amamentação & Amamentação & Amamentação \\
\hline Contato & Presencial & Presencial & Presencial \\
\hline
\end{tabular}

Quadro 1 - Processo de comunicação e seus elementos entre mãe, criança e enfermeira durante a amamentação. 
A amamentação é um ato determinado biologicamente e condicionado socialmente ${ }^{(6)}$. Constitui um momento de intensa comunicação entre mãe e filho, pois a mãe está em contato íntimo com seu filho e utiliza várias formas de comunicação para interagir com ele.

Esperança (remetente) interage verbalmente com a criança no intuito de estimulá-la a mamar; a criança (destinatário) responde com choro; a enfermeira identifica a dificuldade. Conforme mostra a literatura, o primeiro meio de comunicação dos lactentes é o choro; eles demonstram a insatisfação antes do prazer. Apesar das crianças manifestarem diferentes tipos de choro, os pais são capazes de distingui-los e, a partir destas mensagens, interpretam as necessidades dos filhos ${ }^{(7)}$.

Como destinatário, a enfermeira recebe e codifica a mensagem, que é a dificuldade de amamentar a criança, e busca auxiliar no processo. Ela atua como remetente e responde à mãe (destinatário), partindo do princípio segundo o qual sempre ocorre interação ou troca de mensagem no processo comunicativo, porque emissor é receptor e receptor é emissor, o profissional deve agregar habilidades de comunicação para ser efetiva no processo de cuidar $^{(8)}$. O contexto da mensagem é a amamentação e os códigos utilizados são as palavras e o choro. O contato ou canal se dá presencialmente entre os interlocutores.

Esperança (remetente) amamenta e demonstra receio para a enfermeira (destinatário) ao ouvir sons da criança. Diante disto, a enfermeira (remetente) procura confortá-la (destinatário) tentando minimizar seu sentimento de ansiedade. O contexto é a amamentação, o código são as palavras e os sons e o contato também se dá presencialmente. Novamente como afirma a literatura, as vocalizações acompanham o choro e, podem se tornar sílabas e palavras; em torno de dois meses, as crianças emitem sons vocálicos simples ${ }^{(7)}$. Na comunicação relatada, a criança utilizou estas vocalizações prenunciando o choro e demonstrando incômodo, provavelmente devido à forma como era segurada. A mensagem decodificada pela mãe foi a iminência do filho recusar o peito.

$\mathrm{Na}$ análise da verbalização de Esperança, evidenciam-se suas percepções das dificuldades de amamentar. A limitação física interferiu no modo de posicionar a criança trazendo desconforto, ainda mais acentuado com seu crescimento e desenvolvimento. Conhecedora da importância da amamentação e percebendo as dificuldades em dar de mamar, a mãe expressava sentimentos de angústia e tristeza. Comparada com estudo de mães com bebês prematuros, demonstra sofrimento e instabilidade emocional ${ }^{(9)}$. Nesta fase Esperança foi avaliada por enfermeira especialista em aleitamento materno que, após presenciar as circunstâncias em que ocorria o aleitamento, aconselhou não mais se insistir por este caminho em face das dificuldades da mãe e do estresse demonstrado pelo binômio. A partir de então, a criança passou a se alimentar por mamadeira.

Agora Esperança alimenta seu filho por mamadeira, e a criança apresenta um episódio de tosse. O momento comunicativo ocorre da seguinte forma: a mãe (remetente) interage com a criança e a enfermeira (destinatários) e interpreta a tosse como um erro seu cometido durante a alimentação. A enfermeira (remetente) utiliza a verbalização para tranqüilizar a mãe e o faz no modo de comunicação do tipo negação. Segundo defendem teóricos da comunicação, esta forma de reforço comunicativo é acompanhada de comportamento afetivo, e, deste modo, o destinatário se sente respeitado. Embora o emissor não confirme as palavras do destinatário, leva-o a certificar-se do que realmente está acontecendo, e a analisar suas percepções e pensamentos ${ }^{(10)}$. A interação terapêutica no processo comunicativo verbal do profissional durante o cuidado de enfermagem, é percebido pelo paciente com maior ou menor intensidade de atenção e carinho(11).

Como se observou, em virtude das limitações, a mãe cega deve ser apoiada durante a administração da mamadeira até que desenvolva a habilidade de perceber as reações da criança e também, de identificar se ainda há leite na mamadeira mediante verificação do seu peso e reações do volume ao movimento. Independentemente do aleitamento materno, deve-se lembrar que nos primeiros dias de vida do recém-nascido o maior desejo da mãe é permanecer o mais próximo possível dele, da mesma maneira quando estavam intimamente ligados dentro da barriga materna ${ }^{(12)}$.

Ao se referir às funções das mensagens na Teoria da Comunicação Verbal, Jakobson as descreve como emotiva, referencial e conativa ${ }^{(2)}$. Segundo afirma, a função emotiva ou expressiva demonstra diretamente uma expressão da atitude de quem fala com relação 
ao que se está falando. Representa a expressão de determinada emoção, verdadeira ou não. O estrato emotivo da linguagem se manifesta por meio das interjeições que colorem as manifestações verbais. No quadro a seguir, é apresentada a interpretação destas funções de acordo com o observado.

\begin{tabular}{|l|l|}
\hline \multicolumn{1}{|c|}{$\begin{array}{c}\text { Funções das } \\
\text { Mensagens }\end{array}$} & \multicolumn{1}{c|}{ Mãe } \\
\hline Emotiva & $\begin{array}{l}\text { Que foi que a gente conversou hoje de } \\
\text { manhã? A mamãe falou que às vezes pega } \\
\text { você de um jeito que a mamãe não sabe. } \\
\text { Mas a mamãe ama você. Está gostoso? } \\
\text { Muito fofo. Venha cá, meu príncipe! } \\
\text { Êpa! Eita! }\end{array}$ \\
\hline Referencial & $\begin{array}{l}\text { É desse jeito. Ele mama e depois ele solta... } \\
\text { No início ele pega. }\end{array}$ \\
\hline Conativa & Traga para mim!... Ele tem que querer! \\
\hline
\end{tabular}

\section{Quadro 3 - Funções das mensagens identificadas na comunicação verbal da mãe na amamentação.}

Na forma de se referir ao filho, Esperança utiliza constantemente da função emotiva, sobretudo quando expõe a importância e o significado deste em sua vida. Há, também, forte fator emocional expresso quando não consegue amamentar. Ademais se constata a utilização de interjeições, quando as falas da mãe têm função emotiva predominante.

A função referencial direciona o contexto e expressa a informação; está ligada a alguém ou a algo que se fala. Trata-se do contexto da mensagem e é aí onde ocorre a troca de informações $^{(2)}$. Enquanto amamentava, Esperança comunicava-se com a enfermeira e o bebê como se interpretasse e narrasse tentativas, sucessos e insucessos na amamentação; pode-se dizer que decodificava a mensagem para o outro.

Quanto à função conativa, é descrita como a orientação para o destinatário, gramaticalmente expressa mais no vocativo e no imperativo, distanciando-se a princípio de algumas categorias verbais e nominais ${ }^{(2)}$. Esperança raramente utiliza esta forma de expressão da mensagem, possivelmente em virtude da sua situação de vulnerabilidade e dependência diante das limitações. Exemplificando, sua frase voluntariosa é uma ordem, e, mais uma vez, demonstra sua vontade de amamentar: "Traga para mim!... Ele tem que querer!".

\section{Comunicação não verbal}

A comunicação não verbal refere-se a mensagens enviadas por meio de ações e comportamentos em vez de palavras. Expressões faciais, maneirismos, voz, postura e vestimenta representam a maior parte das mensagens enviadas e recebidas. Neste tipo de comunicação, a visão é um dos sentidos mais atuantes. Por meio dela, o ser humano tem a possibilidade de identificar objetos, distinguir cores, tamanhos, formas, e distâncias $^{(8)}$. De acordo com a literatura, a informação visual é mais bem centrada e fidedigna do que a informação auditiva. Porém o cego é uma exceção, pois sua atividade auditiva aprende a selecionar as altas freqüências acústicas, podendo localizar objetos que o rodeiam ${ }^{(4)}$. Como Esperança utiliza a audição com precisão, isto auxilia nas interações com o seu filho.

Consoante observado, a análise da comunicação não verbal mãe-filho se dá em três momentos, sempre com a mãe na cama. Nos dois primeiros, durante a amamentação, Esperança estava deitada e, no outro, sentada. No terceiro momento, administrava leite artificial e estava sentada. Estes momentos foram selecionados evidenciando as condições físicas de Esperança e a posição por ela assumida para alimentar seu filho. E também para mostrar as tentativas, dificuldades e sucessos de alimentar a criança, relacionadas e estas posições e ao aleitamento ou leite artificial.

\begin{tabular}{|l|l|}
\hline \multicolumn{1}{|c|}{ Fatores da comunicação } & \multicolumn{1}{c|}{ Análise } \\
\hline Distância íntima & $\begin{array}{l}\text { Mãe e filho em decúbito } \\
\text { lateral (contato barriga- } \\
\text { barriga). }\end{array}$ \\
\hline Contato físico diminuído & A mãe não transmite afeto. \\
\hline Postura & $\begin{array}{l}\text { Posição da mãe diminuiu o } \\
\text { contato físico com o bebê. }\end{array}$ \\
\hline Eixo sociopeto & $\begin{array}{l}\text { A mãe quer interagir com a } \\
\text { criança. }\end{array}$ \\
\hline Fácies de tristeza e medo & $\begin{array}{l}\text { A mãe teme prejudicar seu } \\
\text { filho por deixar de mamar. }\end{array}$ \\
\hline Cabeça apoiada na cama & $\begin{array}{l}\text { A mãe não consegue ficar } \\
\text { face a face com o filho. }\end{array}$ \\
\hline Ausência de contato visual & $\begin{array}{l}\text { A mãe não direciona a face } \\
\text { ao filho. }\end{array}$ \\
\hline Tom de voz normal & $\begin{array}{l}\text { A mãe freqüentemente } \\
\text { conversa com o bebê. }\end{array}$ \\
\hline
\end{tabular}

\section{Quadro 4 - Análise dos fatores da comunicação não verbal mãe-filho durante a amamentação: mãe deitada.}

Esperança sentia dificuldade para estabelecer interações com o bebê na sua fase inicial e mostrava insegurança ao prestar cuidados. Conhecer as características das interações entre a mãe e o bebê, desde os primeiros dias de vida, quando está se iniciando sua fase de desenvolvimento, é uma importante contribuição para entender o processo de desenvolvimento humano(13)

A amamentação com a mãe deitada propiciou a distância íntima, com o contato barriga da mãe e do filho. Esta postura diminuiu o contato físico o qual fica restrito a uma parte do corpo, dificultando a expressão de carinho entre o binômio. Esperança não consegue segurar a criança nesta posição, e o rosto do bebê voltava-se totalmente para o peito. Diante disto, a criança reage com sinais de desconforto e a mãe interage com ela no intuito de acolhê-la e manter a amamentação. Esperança continua com a cabeça apoiada na cama o que não propicia o contato face a face. Durante todo o período a 
mãe conversa com a criança em tom de voz normal. O rosto é um poderoso canal de interação, sobretudo entre o adulto e a criança: ele é a principal fonte de símbolos a atrair o recém-nascido, pois catalisa sua atenção e provoca uma sensação de bem-estar, base indispensável para a evolução da sociabilidade.

\begin{tabular}{|l|l|}
\hline Fatores da comunicação & \multicolumn{1}{|c|}{ Análise } \\
\hline Distância íntima & Filho nos braços da mãe. \\
\hline Contato físico elevado & $\begin{array}{l}\text { Expressão de afeto por parte } \\
\text { da mãe. }\end{array}$ \\
\hline Postura & $\begin{array}{l}\text { Posição da mãe proporciona } \\
\text { contato físico com o bebê. }\end{array}$ \\
\hline Eixo sociopeto & $\begin{array}{l}\text { A mãe procura interagir } \\
\text { com a criança. }\end{array}$ \\
\hline Fácies de tristeza e medo & $\begin{array}{l}\text { A mãe teme prejudicar seu } \\
\text { filho por deixar de mamar. }\end{array}$ \\
\hline Cabeça baixa & $\begin{array}{l}\text { Vício postural decorrente } \\
\text { da cegueira }\end{array}$ \\
\hline Ausência de contato visual & $\begin{array}{l}\text { A mãe não direciona a face } \\
\text { ao filho. }\end{array}$ \\
\hline Tom de voz normal & $\begin{array}{l}\text { A mãe conversa freqüentemente } \\
\text { com o bebê. }\end{array}$ \\
\hline
\end{tabular}

\section{Quadro 5 - Análise dos fatores da comunicação não verbal mãe-filho durante a amamentação: mãe sentada.}

Esperança deseja amamentar, conhece os benefícios da amamentação, mas teme que seu filho se prejudique. Ela expressou este sentimento verbalmente repetidas vezes. Sua limitação física interferia no posicionamento do filho, dificultava a amamentação e causou desânimo e tristeza na mãe. A amamentação com Esperança sentada propiciou à criança ficar nos braços da mãe, quase sentada, sempre posicionada no braço esquerdo, com a cabeça voltada para trás e com dificuldade para alcançar o bico do peito. Para facilitar a atividade, Esperança colocava o bico do peito entre os dedos e o direcionava à boca do filho.

Com relação aos fatores da comunicação não verbal, a distância predominante nas interações mãe-bebê foi a íntima, com bom contato físico, transmissão do calor humano e dos odores que os encontros pessoais mais íntimos oferecem. Além deste contato, a mãe interagia verbalmente com a criança, demonstrando afeto e carinho.

Conforme exposto, ao amamentar o filho, Esperança manteve-se, predominantemente, na posição deitada e sentada. Desse modo, não mantinha o rosto voltado para o filho e, assim, comprometia a comunicação. Em face da ausência de contato visual do cego, ele não percebe a importância de posicionar seu rosto para a pessoa com que está interagindo, como evidenciado pelas atividades de Esperança, quando dava de mamar nas posições deitada e sentada. Segundo mostra a literatura, desde os primeiros dias de vida do bebê, a mãe serve como mediador de conhecimento, ação e percepção visual. No início da vida do bebê, o rosto é o estímulo visual mais freqüentemente oferecido para ele $\mathrm{e}^{(14)}$. Apesar de Esperança ter freqüentado escola para cegos, não incorporou a atitude educada de direcionar o rosto para com quem fala. Aqui, por se tratar de criança nos primeiros meses de vida, este cuidado deve ser ainda maior e a mãe deve ser orientada sobre isto.

Mesmo com as dificuldades, Esperança amamentou seu filho até por volta dos 45 dias de vida. Lembramos que Esperança foi avaliada por enfermeira especialista em aleitamento materno e esta a aconselhou não mais se insistir por este caminho diante das dificuldades da mãe e do estresse demonstrado pelo binômio. Por esse motivo a criança passou a se alimentar por mamadeira.

\begin{tabular}{|l|l|}
\hline Fatores da comunicação & \multicolumn{1}{|c|}{ Análise } \\
\hline Distância íntima & Filho no braço da mãe. \\
\hline Contato físico elevado & $\begin{array}{l}\text { Expressão de afeto por } \\
\text { parte da mãe. }\end{array}$ \\
\hline Postura (sentada) & $\begin{array}{l}\text { Posição da mãe proporciona } \\
\text { contato físico com o bebê. }\end{array}$ \\
\hline Eixo sociopeto & $\begin{array}{l}\text { A mãe demonstra querer } \\
\text { interagir com a criança. }\end{array}$ \\
\hline Fácies de alegria & $\begin{array}{l}\text { A mãe consegue dar a } \\
\text { mamadeira para seu filho. }\end{array}$ \\
\hline Cabeça baixa & $\begin{array}{l}\text { A mãe permanece com a } \\
\text { cabeça abaixada. }\end{array}$ \\
\hline Ausência de contato visual & $\begin{array}{l}\text { A mãe não direciona a face } \\
\text { ao filho. }\end{array}$ \\
\hline Tom de voz normal & $\begin{array}{l}\text { A mãe freqüentemente } \\
\text { conversa com o bebê. }\end{array}$ \\
\hline
\end{tabular}

\section{Quadro 6 - Análise dos fatores da comunicação não verbal mãe-filho durante a alimentação com mamadeira: mãe sentada.}

Esperança, ao alimentar seu filho com a mamadeira, o segurava com o braço esquerdo apoiado na cama, em posição íntima. Nesta posição expressava afeto com afagos e interação verbal. Sua face demonstrava alegria, pois conseguia alimentar seu filho e estava mais segura após as orientações da especialista em amamentação. Ainda que a posição não fosse totalmente confortável para a criança, Esperança estava despreocupada de colocá-lo no peito. Quando a criança sustentou a cabeça, a mamada apresentou menos dificuldades.

Como menciona a literatura, a carícia é uma expressão de afeto, que aproxima os indivíduos e acalma. Estudo anterior mostrou que a interação face a face é um fator determinante na proximidade entre mãe e filho ${ }^{(12)}$. Embora falte a visão para Esperança, as interações foram permeadas pelo contato físico, 
relações táteis, carícias, afagos e toques localizados; contudo, o fato de a mãe ser cega interferiu no código visual. A mãe não tinha a face direcionada ao filho e freqüentemente mantinha sua cabeça para baixo e, ainda assim a criança procurava olhar a face da mãe durante a amamentação.

Como a comunicação verbal está associada às palavras, o volume da voz do interlocutor é uma comunicação não verbal, e mostra que os tipos de comunicação estão interligados. No volume de voz da mãe, predominou o tom de voz normal. No intuito de acalmar e estimular a criança, a mãe pouco movia as mãos e seus gestos não complementavam a linguagem verbal.

\section{CONCLUSÃO}

A análise da comunicação verbal da mãe cega e com limitação motora com seu filho e o enfermeiro permite afirmar não ter havido prejuízo no estabelecimento das suas relações. No processo de comunicação foram empregados os elementos deste tipo de comunicação, a saber: remetente, destinatário, mensagem, contexto, código e contato. Constantemente a mãe verbalizava com o filho e a enfermeira. Os sons e o choro do seu filho eram mensagens codificadas por ela. Inicialmente, o contexto era a amamentação, mas passou à alimentação em virtude da ocorrência do desmame. Tal fato, como se conclui pela análise, não recebeu influência de uma comunicação verbal ineficiente sendo dependente a situação de limitação motora. Pela análise das funções da comunicação verbal evidenciam-se deficiência da função conativa nas falas da mãe e o predomínio da função emotiva, provavelmente decorrente das condições física e sensorial da mãe que causam instabilidade emocional no cuidado da criança. Ela é dependente da avó em aspectos que vão desde sua locomoção aos cuidados da criança. Dessa forma, sua dependência a limita quanto à expressão de ordens ou imposições. No processo, a mãe verbalizava para a enfermeira seus sentimentos, dúvidas e dificuldades durante a amamentação e esta, ao perceber as mensagens, realizava intervenções para auxiliar.

A análise sobre a comunicação não verbal durante a amamentação mostrou dificuldades decorrentes da limitação sensorial e motora. Por exemplo, a postura deitada foi desfavorável em vários aspectos, entre estes: o contato físico, à transmissão de afeto, o bebê voltar o rosto para a mãe e mamar. Contudo, a postura sentada foi favorável para o contato físico e transmissão de afeto, propiciou o olhar fixo da criança na face da mãe e facilitou a alimentação da criança, tanto por mamadeira como por leite materno.

Segundo aponta a análise das facilidades e dificuldades da amamentação comparadas com a alimentação com mamadeira, para essa mãe a alimentação do filho por mamadeira foi a melhor alternativa, apesar de se reconhecer a importância da amamentação até os seis meses de idade. É necessário ampliar informações sobre o assunto. Estudos desta natureza devem ser aprofundados para a compreensão do processo de comunicação de pessoas com deficiência e a elaboração de modelos que permitam melhorá-los.

\section{REFERÊNCIAS}

1. Swanson V, Power KG. Initiation and continuation of breastfeeding: theory of planned behaviour. J. Adv. Nurs 2005; 50(3):272-82.

2. Jakobson R. Lingüística e comunicação. São Paulo: Cultrix; 2001.

3. Santos CCV, Shiratori K. A influência da comunicação não verbal no cuidado de enfermagem. Rev Bras Enferm 2005; 58(4):434-7.

4. Hall ET. A dimensão oculta. Lisboa: Relógio D’Água Editores Ltda; 1986.

5. Yin RK. Estudo de caso: planejamento e métodos. $3^{\mathrm{a}}$ ed. Porto Alegre: Bookman; 2005.

6. Almeida JAG, Novak FR. Amamentação: um híbrido natureza-cultura. J. Pediatr. 2004; 80(5):119-25.

7. Wong DL. Enfermagem pediátrica: elementos essenciais à intervenção efetiva. $7^{\mathrm{a}}$ ed. Rio de Janeiro: Guanabara Koogan, 2006.

8. Braga EM, Silva MJP. Comunicação competente: visão de enfermeiros especialistas em comunicação. Acta Paul Enferm 2007; 20(4):410-4.

9. Correia LL, Carvalho AEV, Linhares MBM. Verbal contents expressed by mothers of preterm infants with clinical emotional symptoms. Rev Latino-am Enfermagem 2008; 16(1):64-70.

10. Stefanelli MC. A comunicação nos diferentes contextos da enfermagem. $1^{\text {a }}$ ed. São Paulo: Manole; 2005.

11. Ferreira MA. A comunicação no cuidado: uma questão fundamental na enfermagem. Rev. bras. Enferm 2006; 59(3):327-30.

12. Vasconcelos SG, Paiva SS, Galvao MTG. Comunicación proxémica entre madre e hijo en alojamiento conjunto. Rev. Enferm. UERJ 2006; 14(1):37-42.

13. Moura MLS, Ribas AFP, Seabra KDAC, Pessoa LF, Ribas Junior RDEC, Nogueira SE. Interações iniciais mãe-bebê. Psicol. Ref. Crítica 2004; 17(3):295-302.

14. Faquinello $P$, Collet $N$. Vínculo afetivo mãe/criança na unidade de alojamento conjunto pediátrico. Rev. Gaúcha Enferm 2003; 24(3):294-304. 